\title{
BIODETERIORAÇÃO DE PRODUTOS À BASE DA MADEIRA DE CEDRO AUSTRALIANO (Toona ciliata M. Roem. var. australis)
}

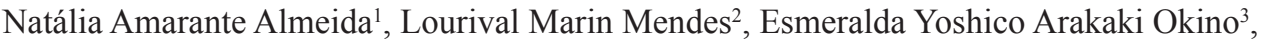 \\ Alencar Garlet ${ }^{4}$, Fábio Akira Mori ${ }^{5}$, Rafael Farinassi Mendes ${ }^{6}$
}

(recebido: 4 de maio de 2010; aceito: 29 de setembro de 2011)

RESUMO: Conduziu-se este trabalho, com os objetivos de: avaliar a resistência natural de painéis reconstituídos e da madeira de Toona ciliata ao ataque de fungos por meio de ensaio acelerado de laboratório; caracterizar seus componentes anatômicos segundo IAWA; quantificar os valores de lignina solúvel e insolúvel; das amostras por hidrólise ácida e os parâmetros colorimétricos antes e após o ataque dos fungos, utilizando o sistema CIE-L*a*b*(1976). A madeira sólida foi classificada como moderadamente e altamente resistente ao fungo de podridão branca (Trametes versicolor) e parda (Gloeophyllum trabeum). Os painéis OSB foram resistentes e moderadamente resistentes à podridão branca e para a parda, foram altamente resistentes. A variação de espécies e partículas não teve efeito positivo nos tratamentos. Com relação à madeira, ambos os fungos apresentaram inibição, em razão da presença de resina fenólica. Os aglomerados foram classificados como moderadamente resistentes à podridão branca. Os tratamentos T2 (cedro) e T4 (cedro-eucalipto) foram resistentes, mas o T3 (cedro-pinus) não resistiu ao ataque do fungo de podridão parda. A resina uréia-formaldeído não inibiu os ataques como a fenólica. Anatomicamente, a espécie apresentou textura média, linhas vasculares retilíneas, cheiro agradável ao corte e superfície radial pouco lustrosa. Sua estrutura anatômica favoreceu a colonização das hifas dos fungos. Todos os tratamentos ocasionaram escurecimento, após o ataque do fungo G. trabeum, com variação total da cor. Observou-se que, com a perda de massa, houve aumento nos teores de lignina insolúvel, para todos os tratamentos, indicando que essa propriedade química é um fator determinante na resistência da madeira ao ataque dos fungos avaliados.

Palavras-chave: Toona ciliata, biodeterioração, painéis reconstituídos.

\section{BIODETERIORATION OF PRODUCTS MADE FROM AUSTRALIAN CEDAR (Toona ciliata M. Roem. var. australis)}

\begin{abstract}
The objectives of this study were to evaluate the natural resistance of composite and solid wood panels from Toona ciliata to fungal attack through accelerated laboratory testing, to characterize the anatomical components of the wood according to IAWA, to quantify the soluble and insoluble lignin contents by acid hydrolysis and to determine the colorimetric parameters before and after fungal attack by using the CIE-L*a*b*(1976) system. Solid wood was classified as moderately and highly resistant to white-rot fungus (Trametes versicolor) and to brown-rot fungus (Gloeophyllum trabeum). OSB panels were found to be resistant and moderately resistant to white-rot fungus and highly resistant to brown-rot fungus. Variation in species and particle type did not have a positive effect on the treatments. As regards the wood, both fungi were inhibited by the presence of phenolic resin. Particleboard panels were classified as moderately resistant to white-rot fungus. Treatments $T 2$ (cedar) and T4 (cedar-eucalyptus) were resistant while treatment $T 3$ (cedar-pine) was not resistant to attack by brown-rot fungus. The urea-formaldehyde resin failed to inhibit attack in the same way the phenolic resin did. Anatomically, the species was found to have medium texture, straight vessel lines, pleasant smell after incision and poor luster on the radial surface. Its anatomical structure favored colonization by the threadlike filaments of the fungi. All treatments caused wood darkening after attack by the G. trabeum fungus, with total variation in color. It was observed that with weight loss an increase followed in insoluble lignin contents, in all treatments, indicating that this chemical property is a determining factor in wood resistance to the attack of the fungi being evaluated.
\end{abstract}

Key words: Toona ciliata, biodeterioration, composite wood panels.

\footnotetext{
${ }^{1}$ Bióloga, Mestre em Ciência e Tecnologia da Madeira - Universidade Federal de Lavras/UFLA - Cx. P. 3037 - 37200-000 - Lavras, MG natamarant@gmail.com

${ }^{2}$ Engenheiro Florestal, Professor Dr. em Engenharia Florestal - Departamento de Ciências Florestais - Universidade Federal de Lavras/UFLA Cx. P. 3037 -37200-000 - Lavras, MG - lourival@dcf.ufla.br

${ }^{3}$ Engenheira Química, Mestre em Química - Laboratório de Produtos Florestais/LPF - Ministério do Meio Ambiente/MMA-70000-000 - Brasília, DF esmeralda.okino@ibama.gov.br

${ }^{4}$ Engenheiro Florestal, Analista Ambiental - Laboratório de Produtos Florestais/LPF - Serviço Florestal Brasíleiro/SFB - 70818-900 - Brasília, DF alencar.garlet@ibama.gov.br

${ }^{5}$ Engenheiro Florestal, Professor Dr. em Ciências Florestais - Departamento de Ciências Florestais - Universidade Federal de Lavras/UFLA Cx. P. 3037 -37200-000 - Lavras, MG - morif@dcf.ufla.br

${ }^{6}$ Engenheiro florestal, Doutorando em Ciência e Tecnologia da Madeira - Universidade Federal de Lavras/UFLA - Cx. P. 3037 - $37200-000$ Lavras, MG - rafaelfarinassi@gmail.com
}

Cerne, Lavras, v. 18, n. 1, p. 17-26, jan./mar. 2012 


\section{INTRODUÇÃO}

Diante da crescente demanda por madeira reflorestada e painéis reconstituídos, torna-se primordial a melhoria da qualidade desses produtos. Uma das principais propriedades das madeiras é a sua maior ou menor suscetibilidade em ser atacada por organismos xilófagos. Dentre estes, destacam-se os fungos apodrecedores pertencentes a classes dos basidiomicetos, responsáveis pela podridão parda e branca, que possuem características enzimáticas próprias quanto à decomposição de alguns constituintes da madeira.

Segundo Lepage (1986), a madeira sob ataque de fungos apresenta alterações na composição química, redução da resistência mecânica, diminuição de massa, modificação da cor natural, aumento da permeabilidade, redução da capacidade acústica, aumento da inflamabilidade, diminuição do poder calorífico e maior propensão ao ataque de insetos, comprometendo, dessa forma, a sua qualidade e inviabilizando a sua utilização para fins tecnológicos.

A durabilidade da madeira depende das vias de acesso para os organismos se fixarem e de sua composição química. $\mathrm{O}$ acesso à penetração das hifas depende da natureza, distribuição e tamanho dos elementos celulares ou anatômicos da madeira, sendo os axiais o principal meio, seguido pelos elementos radiais e tangenciais (EATON; HALE, 1993). Além desses elementos, há as barreiras naturais à penetração dos fungos, como as tiloses, pontoações, gomas e resinas. Os principais fatores químicos que influenciam a durabilidade natural da madeira são os próprios polímeros da parede celular e os extrativos presentes na forma de terpenos, e polifenóis condensados como quinonas, lignanas, taninos e estilbenos.

A madeira do cedro australiano (Toona ciliata) vem se destacando no Brasil em decorrência das altas taxas de crescimento e boa adaptabilidade às condições edafoclimáticas, principalmente nas regiões sudeste de Minas Gerais e sul da Bahia. Sabe-se que sua madeira é rica em extrativos, os quais podem auxiliar no aumento da durabilidade natural. É uma espécie promissora para plantações comerciais por causa da qualidade de sua madeira e elevada resistência ao broqueador das pontas (Hypsipyla grandella Zeller), que afeta os cedros nativos (MANGLIAVORI et al., 2003).

Há, portanto, grande interesse na escolha da madeira para seu uso, verificando que a mistura de espécies mais duráveis com as menos duráveis pode ser uma saída no quesito prolongar a vida útil de seus subprodutos, evitando o uso de preservantes químicos.

Cerne, Lavras, v. 18, n. 1, p. 17-26, jan./mar. 2012
Assim, conduziu-se este trabalho com os objetivos de estudar a resistência da madeira e de painéis reconstituídos de Toona ciliata ao ataque de fungos xilófagos; caracterizar os componentes anatômicos da madeira; determinar os parâmetros colorimétricos das amostras antes e após o ataque dos fungos apodrecedores e quantificar os teores de lignina solúvel e insolúvel antes e após o ataque dos fungos.

\section{MATERIAL E MÉTODOS}

O material utilizado neste trabalho foi a madeira de cedro australiano (Toona ciliata M. Roem) com idade de 18 anos, oriunda de Marechal Floriano-ES.

\subsection{Caracterização anatômica}

Para a caracterização anatômica da madeira foram utilizadas três árvores de cedro australiano. De cada árvore foi retirado um disco no DAP e de cada disco retiraram-se três corpos-de-prova para o estudo anatômico. Adotou-se a terminologia recomendada pela International Association of Wood Anatomy - IAWA (1989).

\subsection{Biodeterioração}

Os tratamentos submetidos ao ensaio acelerado de laboratório basearam-se na metodologia proposta pela norma ASTM D 2017 (AMERICAN SOCIETY FOR TESTING AND MATERIALS - ASTM, 2005) com algumas modificações. Foram empregadas duas espécies de fungos xilófagos: Trametes versicolor (Linnaeus ex Fries) Pilat, (podridão branca); e Gloeophyllum trabeum (Persoon. ex Fries.) Murr. (podridão parda), pertencentes à coleção do Laboratório de Produtos Florestais do Serviço Florestal Brasileiro (LPF/SFB). Os tratamentos ensaiados se constituíram de madeira sólida de cedro australiano (Toona ciliata M. Roem.), de painéis aglomerados de cedro e em mistura de cedro com a madeira de pinus e eucalipto; de painéis OSB de cedro e em mistura de cedro com a madeira de pinus e eucalipto em diferentes camadas.

Os painéis aglomerados foram produzidos com a densidade nominal de $0,70 \mathrm{~g} / \mathrm{cm}^{3}$ e adesivo uréiaformaldeído em um teor de $9 \%$ (base massa seca das partículas). Enquanto que os painéis OSB foram produzidos com densidade nominal de $0,62 \mathrm{~g} / \mathrm{cm}^{3}$, adesivo fenol-formaldeído, também com o teor de $9 \%$ (base massa seca das partículas) e proporção das camadas de 25/50/25 (face/miolo/face), as quais foram dispostas de forma que a camada do miolo ficou perpendicular às camadas das faces, sendo que no caso dos painéis com mistura de tipos de madeira, cada espécie de madeira foi colocada de forma separada em cada uma das camadas dos painéis. 
A madeira de Cedro australiano utilizada nesse estudo apresentou densidade básica média de $0,32 \mathrm{~g} / \mathrm{cm}^{3}$. Na Tabela 1, apresenta-se o plano experimental adotado neste trabalho.

Foi adotado o delineamento experimental inteiramente casualizado, com 9 repetições para cada fungo. Após 12 semanas de exposição aos fungos xilófagos, a resistência da madeira e dos painéis foi avaliada por meio da porcentagem da perda de massa, conforme norma ASTM D 2017 (ASTM, 2005).

\subsection{Determinação da cor das madeiras e dos painéis}

A metodologia adotada para a determinação dos parâmetros colorimétricos foi o sistema CIELAB. Para determinar as alterações na cor da madeira e dos painéis após o ataque dos fungos, utilizou-se a variação total da cor $\left(\Delta \mathrm{E}^{*}\right)$, metodologia que leva em conta as diferenças das coordenadas cromáticas e de luminosidade, fornecendo uma visão mais ampla sobre o desempenho da madeira e dos painéis sob ataque dos fungos.

\subsection{Determinação da lignina solúvel e insolúvel}

Para este ensaio foram utilizados todos os corpos-deprova, antes e após o ataque dos fungos. Foram determinados os teores de lignina solúvel e insolúvel, por meio da hidrólise ácida da amostra livre de extrativo, seguindo a norma National Renewable Energy Laboratory (1996).

\section{RESULTADOS E DISCUSSÃO}

\subsection{Caracterização anatômica da madeira}

A madeira do cedro australiano tem como características gerais textura média, linhas vasculares retilíneas, grã direita ou ligeiramente irregular (inclinada), cheiro agradável ao corte, sem gosto, superfície radial pouco lustrosa, madeira macia ao corte e cerne begerosado, distinto do alburno marrom-claro. A estatística descritiva dos componentes anatômicos da madeira das três árvores com 18 anos de idade, para a localidade de Marechal Floriano/ ES está apresentada na Tabela 2.

Tabela 1 - Plano experimental.

Table 1 - Experimental design.

\begin{tabular}{|c|c|c|c|}
\hline Tratamento & Descrição & Código & Proporção $(\%)$ \\
\hline $\mathrm{T} 1$ & Madeira sólida de cedro australiano & - & - \\
\hline $\mathrm{T} 2$ & Painel aglomerado de cedro australiano & $\mathrm{C}$ & 100 \\
\hline $\mathrm{T} 3$ & Painel aglomerado com mistura de cedro e pinus & $\mathrm{CP}$ & $50 ; 50$ \\
\hline $\mathrm{T} 4$ & Painel aglomerado com mistura de cedro e eucalipto & $\mathrm{CE}$ & $50: 50: 00$ \\
\hline T5 & Painel OSB de cedro australiano & $\mathrm{C}$ & 100 \\
\hline T6 & Painel OSB de pinus & $\mathrm{P}$ & 100 \\
\hline $\mathrm{T} 7$ & Painel OSB de eucalipto & $\mathrm{E}$ & 100 \\
\hline $\mathrm{T} 8$ & Painel OSB com mistura de cedro e pinus & $\mathrm{CPC}$ & $25: 50: 25$ \\
\hline T9 & Painel OSB com mistura de pinus e cedro & PCP & $25: 50: 25$ \\
\hline $\mathrm{T} 10$ & Painel OSB com mistura de cedro e eucalipto & CEC & $25: 50: 25$ \\
\hline $\mathrm{T} 11$ & Painel OSB com mistura de eucalipto e cedro & ECE & $25: 50: 25$ \\
\hline
\end{tabular}

Tabela 2 - Valores médios das dimensões dos vasos, fibras e raios das árvores de cedro australiano com idade de 18 anos.

Table 2 - Mean size of vessels, fibers and rays of Australian cedar trees at age 18.

\begin{tabular}{|c|c|c|c|c|c|c|c|c|}
\hline \multicolumn{9}{|c|}{ Análise anatômica } \\
\hline \multirow{2}{*}{ Árvore } & \multicolumn{2}{|c|}{$\operatorname{Vasos}(\mu \mathrm{m})$} & \multicolumn{3}{|c|}{ Fibras $(\mu \mathrm{m})$} & \multicolumn{3}{|c|}{ Raios $(\mu \mathrm{m})$} \\
\hline & Comp. & Diâm. & Comp. & Parede & Lume & Comp. & Larg. & Freq. \\
\hline 1 & 330,43 & 175,05 & 1070,96 & 2,98 & 16,54 & 0,39 & 50,36 & 5,98 \\
\hline 2 & 363,84 & 150,90 & 1092,20 & 3,26 & 17,38 & 0,36 & 42,74 & 5,78 \\
\hline 3 & 355,17 & 163,00 & 936,49 & 3,18 & 16,93 & 0,36 & 43,60 & 5,66 \\
\hline Média & 349,81 & 162,98 & 1033,22 & 3,14 & 16,95 & 0,37 & 45,57 & 5,66 \\
\hline $\mathrm{CV}(\%)$ & 4,96 & 7,41 & 8,17 & 4,63 & 2,47 & 3,49 & 9,16 & 2,78 \\
\hline
\end{tabular}

Cerne, Lavras, v. 18, n. 1, p. 17-26, jan./mar. 2012 
A espécie apresentou camadas de crescimento distintas (Figura 1B), em razão da diferenciação na espessura da parede das fibras. Os vasos apresentaram porosidade em anéis semiporosos; sendo vasos geminados $38,81 \%$ (Figura 1B), ocorrendo também solitários $61,19 \%$ e múltiplos de 3. A frequência apresentou valores de $7,78 \mathrm{~mm}^{2}$ a $8,04 \mathrm{~mm}^{2}$, com uma média de $7,91 \mathrm{~mm}^{2} \mathrm{e}$ desvio padrão de $0,13 \mathrm{~mm}^{2}$; placa de perfuração simples e apêndice presente em uma ou ambas as extremidades; vasos desobstruídos; pontuações intervasculares alternas
(Figura 1A); de formato arredondado. Parênquima axial paratraqueal: escasso. Parênquima marginal terminal. Fibras: libriformes com pontuações muito pequenas. Raios: parênquima radial heterogêneo do tipo III; possui dois tipos distintos; presença de amido (Figura 1C); raros cristais (Figura 1D) e sílicas (Figura 1E); ocorrendo multisseriados e unisseriados.

Possui vasos com porosidade em anéis semiporosos, em arranjos radiais com placas de perfuração simples, característicos de espécies da família Meliaceae.
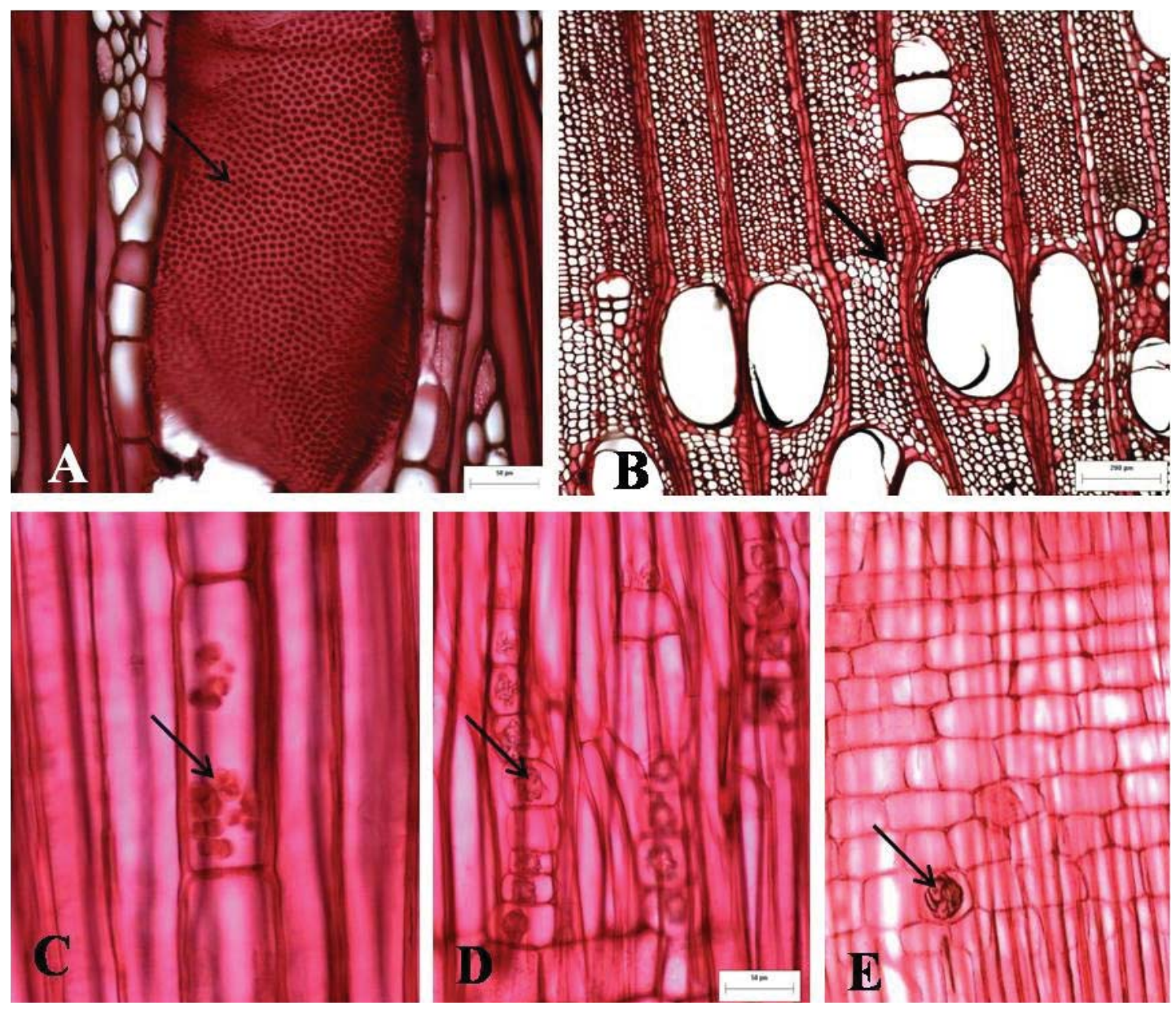

Figura 1 - Aspectos anatômicos gerais da madeira de cedro australiano com 18 anos. A: Pontoações intervasculares (seta); B: plano transversal (seta) demarcando a camada de crescimento distinta devido à diferenciação na espessura da parede das fibras, evidenciando vasos solitários e geminados, com contorno arredondado e parênquima axial escasso; C: presença de células de amido no parênquima radial ; D: cristais no parênquima radial; E: sílica no parênquima radial.

Figure 1 - General anatomical aspects of Australian cedar wood at age 18. A: intervessel pits (arrow); B: cross section (arrow) demarcating a distinct growth layer due to differentiation in fiber wall thickness, showing single and paired vessels, a rounded outline and scanty axial parenchyma; $C$ : presence of starch cells in the radial parenchyma; D: crystals in the radial parenchyma; E: silica in the radial parenchyma.

Cerne, Lavras, v. 18, n. 1, p. 17-26, jan./mar. 2012 
Além desses, o cedro australiano apresenta vasos em anéis semiporosos, como o cedro nativo (CORADIN; CAMARGOS, 2002; CORADIN et al., 1991).

\subsection{Resistência a biodeterioração}

\subsubsection{Madeira de cedro australiano}

A madeira de cedro australiano é moderadamente resistente com perda de massa de $27,79 \%$ em relação ao fungo Trametes versicolor. Frente ao Gloeophyllum trabeum, a madeira de cedro australiano é altamente resistente com perda de massa de $2,93 \%$, de acordo com a classificação sugerida pela norma ASTM D 2017 (ASTM, 2005). Esse fato corrobora a assertiva de que fungos de podridão parda preferencialmente deterioram as coníferas e os de podridão branca as folhosas (ZABEL; MORREL, 1992).

Oliveira et al. (2005) estudaram a influência dos extrativos na resistência ao apodrecimento do cedro (Cedrela fissilis Vell.) causado pelo fungo Gloeophyllum trabeum. Os referidos autores concluíram que a madeira do cedro é naturalmente resistente, e que os solventes utilizados não foram capazes de retirar os componentes químicos responsáveis pela resistência ao apodrecimento causado pelo fungo de podridão parda.

No estudo de Carneiro et al. (2009) com a espécie Cedrela odorata, foi obtida uma perda de massa de $12 \%$ para o Gloeophyllum trabeum e de $22 \%$ para o Trametes versicolor, ambos classificados como resistentes. Tal comportamento diferiu do encontrado neste trabalho, com a madeira da mesma família, a do cedro australiano, pois o Gloeophyllum trabeum foi classificado como altamente resistente e o Trametes versicolor como moderadamente resistente.

Como para o fungo $T$. versicolor a madeira de Cedro australiano foi classificada como moderadamente resistente, de acordo com os critérios da norma ASTM D 2017 (ASTM, 2005), para fins de uso da madeira, os resultados desse ensaio e as informações da literatura levam a crer que o cedro australiano é uma espécie indicada para usos onde as peças não ficarão expostas à umidade, tais como usos internos. Sendo que, para usos em situações de alto risco de apodrecimento (contato direto com o solo ou água), a espécie não é indicada, a menos que seja submetida a algum tratamento preservante (DIROL; DEGLISE, 2001).

O desempenho do cedro australiano durante o ensaio de apodrecimento pode estar relacionado à sua estrutura anatômica. Os dados anatômicos indicam que a espécie é pouco porosa com diâmetro médio e porosidade em anéis semiporosos e, esse fato, está diretamente ligado ao fluxo de líquidos e ao acesso de fungos. De acordo com Richter e Burger (1978), espécies muito porosas são menos resistentes quando comparadas com as menos porosas. No entanto, a densidade básica dessa espécie é baixa $(0,32 \mathrm{~g} /$ $\mathrm{cm}^{3}$ ) o que pode ter facilitado a penetração das hifas, além do fato de que, ao analisar os raios do cedro australiano, verificou-se a presença de células de amido, as quais são uma fonte de alimento para os fungos.

\subsubsection{Painéis aglomerados}

$\mathrm{Na}$ Tabela 3, apresentam-se os valores médios das porcentagens de perda de massa dos painéis aglomerados e suas respectivas classificações de resistência, de acordo com a norma ASTM D 2017 (ASTM, 2005).

Tabela 3 - Média da perda de massa dos painéis aglomerados expostos aos fungos Trametes versicolor e Gloeophyllum trabeum e respectiva classe de resistência.

Table 3-Mean weight loss for particleboard panels exposed to Trametes versicolor and Gloeophyllum trabeum fungi, and respective resistance rating.

\begin{tabular}{ccccc}
\hline \multicolumn{4}{c}{ Perda de massa (\%) e classe de resistência } \\
\hline Tratamentos aglomerado & T. versicolor & Classificação & G. trabeum & Classificação \\
\hline T2 & $41,9(2,20)$ B & MR & $17,1(3,40)$ A & R \\
T3 & $33,3(0,02)$ A & MR & $48,7(0,01)$ B & NR \\
T4 & $40,2(0,02)$ B & MR & $11,9(0,01)$ A & R \\
\hline
\end{tabular}

MR: Moderadamente resistente; R: Resistente; NR: Não resistente.

Médias seguidas pela mesma letra na coluna não diferem estatisticamente entre si, pelo Teste Scott-Knott a 5\% de probabilidade. Dentro dos parênteses se encontram os desvios-padrão.

MR: Moderately resistant; $R$ : Resistant; NR: Nonresistant.

Means followed by the same letter in a column are not statistically different by the Scott-Knott test at the 5\% probability level.

Standard deviations are in parentheses.

Cerne, Lavras, v. 18, n. 1, p. 17-26, jan./mar. 2012 
Somente os painéis aglomerados do tratamento T3 (CP) apresentaram diferença estatística aos demais tratamentos em relação ao ataque do fungo $T$. versiclor, obtendo assim o menor valor médio de perda de massa. Esse comportamento é decorrente dos fungos de podridão branca deteriorarem preferencialmente folhosas, resultando em uma menor perda de massa no tratamento T3, o qual apresentou a mistura da madeira de pinus com a madeira de cedro. Apesar disso, de acordo com a classificação da norma ASTM D2017 (ASTM, 2005), todos os tratamentos com os painéis aglomerados foram considerados como de resistência moderada.

Já, em relação ao fungo G. trabeum, o tratamento T3 também foi o único que se diferenciou estatisticamente dos demais, porém apresentando o maior valor médio de perda de massa, o que é decorrente, justamente, do fato de que fungos de podridão parda deterioram preferencialmente coníferas. Nesse caso, em relação à classificação da norma ASTM D2017 (ASTM, 2005) os painéis do tratamento T3 foram considerados como não resistentes, enquanto que os demais tratamentos foram considerados como resistentes.

Comparativamente à madeira sólida, ambos os fungos não apresentaram certa inibição diante da resina uréia-formaldeído dos aglomerados. Isso decorrente do fato de que essa resina interage com água ou umidade do ar, não conferindo resistência à absorção e ao inchamento como a fenólica, permitindo, assim, que as amostras atingissem o teor de umidade necessário ao crescimento e atuação dos fungos xilófagos. Esses dados foram confirmados por Kartal e Green (2003), os quais afirmaram que as resinas uréicas não são resistentes à água, e que o inchamento das amostras proporciona maior acesso dos fungos às fibras da madeira.

\subsubsection{Painéis OSB}

Na Tabela 4, apresentam-se os valores médios das porcentagens de perda de massa dos painéis OSB e suas respectivas classificações de resistência de acordo com a norma ASTM D 2017 (ASTM, 2005).

$\mathrm{O}$ fungo Trametes versicolor ocasionou nas chapas OSB do tratamento T6 (P) e tratamento T8 (CPC) menor perda de massa, sendo classificados como resistentes, porém, somente o painel do T6 $(\mathrm{P})$ apresentou diferença significativa dos demais tratamentos, obtendo, assim, a menor perda de massa. Os demais tratamentos foram classificados como moderadamente resistentes de acordo com a norma ASTM D2017 (ASTM, 2005).

Enquanto que em relação ao fungo Gloeophylum trabeum, todos os painéis foram classificados como altamente resistentes de acordo com a norma ASTM D2017 (ASTM, 2005). Apesar disso, o tratamento T9 (PCP) apresentou-se diferente estatisticamente dos demais, obtendo assim a maior perda de massa.

Tabela 4 - Média da perda de massa dos painéis OSB expostos aos fungos Trametes versicolor e Gloeophyllum trabeum e as respectivas classes de resistência.

Table 4 - Mean weight loss for OSB panels exposed to Trametes versicolor and Gloeophyllum trabeum fungi and respective resistance rating.

\begin{tabular}{clccc}
\hline \multicolumn{4}{c}{ Perda de massa (\%) e classe de resistência } \\
\hline Tratamentos OSB & T. versicolor & Classificação & G. trabeum & Classificação \\
\hline T5 & $30,8(2,9) \mathrm{B}$ & $\mathrm{MR}$ & $3,4(2,6) \mathrm{A}$ & $\mathrm{AR}$ \\
T6 & $15,5(8,2) \mathrm{A}$ & $\mathrm{R}$ & $2,8(0,5) \mathrm{A}$ & $\mathrm{AR}$ \\
T7 & $37,4(7,8) \mathrm{B}$ & $\mathrm{MR}$ & $4,3(0,2) \mathrm{A}$ & $\mathrm{AR}$ \\
T8 & $23,7(10,43) \mathrm{B}$ & $\mathrm{R}$ & $1,9(0,3) \mathrm{A}$ & $\mathrm{AR}$ \\
T9 & $31,5(21,4) \mathrm{B}$ & $\mathrm{MR}$ & $10,0(6,7) \mathrm{B}$ & $\mathrm{AR}$ \\
T10 & $29,2(5,6) \mathrm{B}$ & $\mathrm{MR}$ & $4,0(1,8) \mathrm{A}$ & $\mathrm{AR}$ \\
T11 & $34,7(12,4) \mathrm{B}$ & MR & $2,4(0,7) \mathrm{A}$ & $\mathrm{AR}$ \\
\hline
\end{tabular}

MR:moderadamente resistente; R: resistente; AR: altamente resistente.

Médias seguidas pela mesma letra na coluna não diferem estatisticamente entre si, pelo Teste Scott-Knott a 5\% de probabilidade. Dentro dos parênteses se encontram os desvios-padrão.

$M R$ : moderately resistant; $R$ : resistant; AR: highly resistant.

Means followed by the same letter in a column are not statistically different by the Scott-Knott test at the 5\% probability level. Standard deviations are in parentheses.

Cerne, Lavras, v. 18, n. 1, p. 17-26, jan./mar. 2012 
Na comparação dos painéis do T5 (C) e da sobreposição de camadas do T8 (CPC), em relação ao fungo T. versicolor, os valores de perda de massa para $\mathrm{T} 5$ que foi de $30,8 \%$ foi levemente superior ao do $\mathrm{T} 8$ que foi de $23,7 \%$. Esse mesmo efeito, apesar de que em menor proporção, também foi verificado no painel OSB com a sobreposição em camadas de cedro e eucalipto (T10, CEC) cuja perda de massa foi de $29,2 \%$. Isso leva a considerar que a sobreposição de camada de espécies induziu um pequeno efeito inibitório ao ataque do fungo de podridão branca. $\mathrm{O}$ mesmo não foi observado para o fungo de podridão parda (G. trabeum).

De forma geral, considerando apenas o cedro australiano, as perdas de massa da madeira de cedro (T1), do painel OSB de cedro (T5, C) e do painel aglomerado de cedro $(\mathrm{T} 2, \mathrm{C})$ foram de $27,8 \%, 30,8 \%$ e $41,2 \%$, respectivamente, quando expostos ao fungo de podridão branca Trametes versicolor. O incremento na perda de massa dos painéis pode estar associado à maior área superficial das partículas e maior facilidade de acesso à penetração das hifas (vazios interpartículas). Esse mesmo comportamento também foi constatado para o fungo de podridão parda Gloeophyllum trabeum, cuja perda de massa foi de $2,9 \%, 3,4 \%$ e $17,1 \%$, respectivamente.

\subsection{Análise colorimétrica}

Na Figura 2, ilustram-se as variações ocorridas na variação total da cor $\left(\Delta \mathrm{E}^{*}\right)$ da madeira sólida e dos tratamentos aglomerados, observados após o ataque dos fungos, enquanto, na Figura 3, ilustram-se as variações ocorridas nos painéis OSB.

Em comparação dos dois tipos de fungos, a variação total de cor $\left(\Delta \mathrm{E}^{*}\right)$ foi maior após o ataque do fungo de podridão parda G. trabeum, tanto para a madeira sólida de cedro australiano (T1), como para os painéis aglomerados de cedro (T2, C), da mistura de cedro e pinus (T3, CP) e da mistura de cedro e eucalipto (T4, CE).

As variáveis colorimétricas são sensíveis, pois detectam qualquer modificação, a exemplo do painel aglomerado de mistura de cedro e pinus (T3, CP) o qual foi o mais atacado pelo fungo de podridão parda, com perda de massa de 47,88\% e, na análise colorimétrica, esse fato foi confirmado, apresentando uma variação total de cor de 22,9.

O mesmo ocorreu com os painéis OSB (Figura 3), com os painéis produzidos com sobreposição de camadas de pinus e cedro (T9, PCP) que apresentou a maior variação de cor de 24,8 , corroborando com a maior perda de massa de $10 \%$ quando exposto ao fungo de podridão

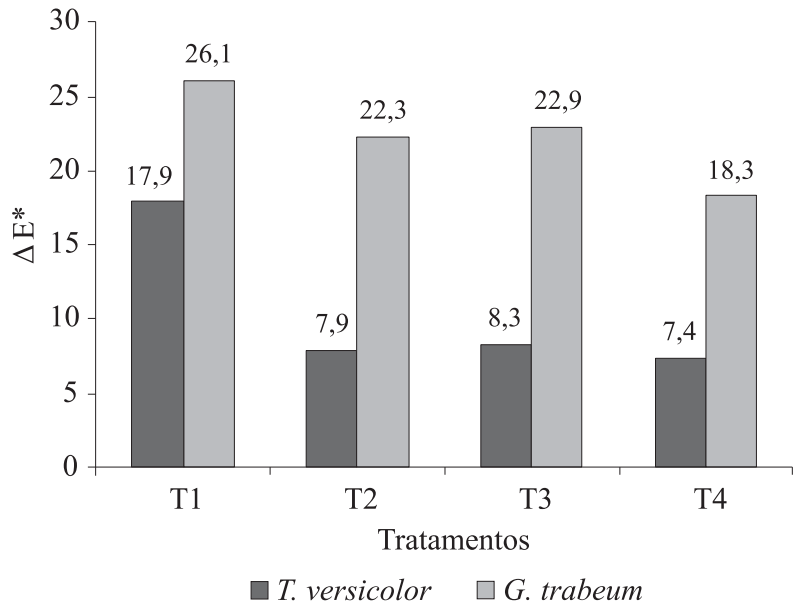

Figura 2 - Valores médios da variação da cor $\Delta \mathrm{E}^{*}$ da madeira de cedro australiano e dos painéis aglomerados expostos aos fungos Trametes versicolor e Gloeophyllum trabeum.

Figure 2 - Mean values of color variation $\left(\Delta E^{*}\right)$ for Australian cedar wood and particleboard panels exposed to Trametes versicolor and Gloeophyllum trabeum fungi.

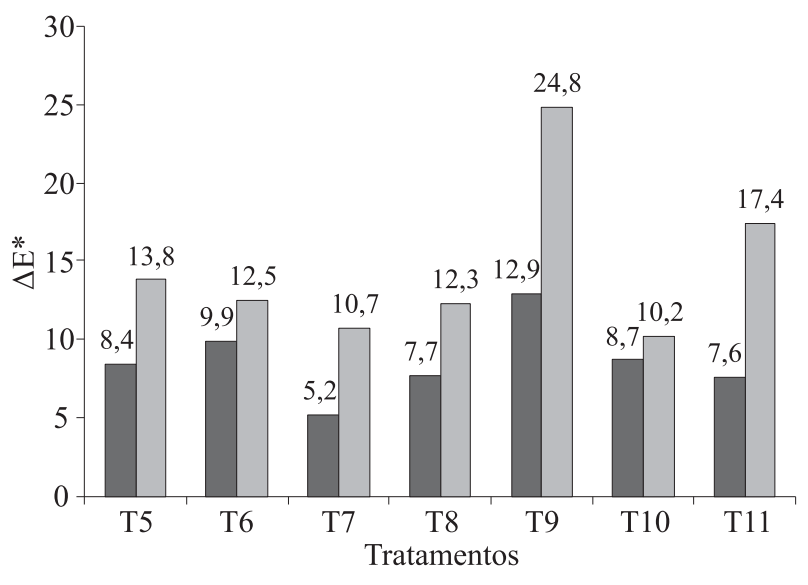

$\square$ T. versicolor $\square$ G. trabeum

Figura 3 - Valores médios da variação da cor $\Delta \mathrm{E}^{*}$ da madeira de cedro australiano e dos painéis OSB expostos aos fungos Trametes versicolor e Gloeophyllum trabeum.

Figure 3 - Mean values of color variation $\left(\Delta E^{*}\right)$ for Australian cedar wood and OSB panels exposed to Trametes versicolor and Gloeophyllum trabeum fungi.

parda Gloeophyllum trabeum, enquanto o painel OSB de pinus $(T 6, P)$ não obteve esse escurecimento, em razão da pequena perda de massa $(2,80 \%)$. Esse fato corrobora com os resultados de Lepage (1986) que cita que a madeira atacada por fungos de podridão parda apresenta-se, em

Cerne, Lavras, v. 18, n. 1, p. 17-26, jan./mar. 2012 
estágios iniciais, ligeiramente escurecida, assumindo uma coloração pardo-escura, à medida que o apodrecimento progride, ou seja, há o acúmulo de resíduos de lignina modificada ou oxidada.

A madeira de cedro australiano apresentou maior variação total de cor $\left(\Delta \mathrm{E}^{*}\right)$, quando comparada com os painéis aglomerados, quando expostos aos fungos de podridão parda e branca. Isso pode ser explicado, pois a madeira de cedro, apesar de sua menor densidade em relação ao painel aglomerado, possui uma superfície mais homogênea do que o painel, que possui superfície mais irregular, provocando maior dispersão da luz ao se fazer as medições no espectrofotômetro.

\subsection{Lignina solúvel e insolúvel da madeira e dos painéis} antes e após o ataque dos fungos

$\mathrm{Na}$ Tabela 5, estão representadas as porcentagens de lignina solúvel e insolúvel da madeira sólida do cedro australiano, dos painéis aglomerados e dos painéis OSB antes e após o ataque dos fungos de podridão branca (Trametes versicolor) e podridão parda (Gloeophyllum trabeum).

Ao analisar os dados da madeira sólida, percebe-se que a madeira não atacada apresentou $25,72 \%$ de lignina insolúvel e, à medida que ocorre a perda de massa, há um aumento na porcentagem de lignina insolúvel. Isso ocorre, pelo fato de que os outros polímeros da madeira são inicialmente mais atacados, por possuir uma característica menos recalcitrante que o da lignina, aumentando, portanto, sua porcentagem relativa. Com relação à madeira de cedro australiano (T1), o maior teor de lignina insolúvel foi de $41,36 \%$ quando exposta ao fungo de podridão branca T. versicolor, cuja perda de massa foi de $27,79 \%$.

Todos os tratamentos de painéis aglomerados ( $\mathrm{T} 2$, T3, T4), quando expostos ao fungo de podridão parda G.trabeum apresentaram um aumento no teor de lignina insolúvel, comparativamente aos painéis expostos ao fungo de podridão branca Trametes versicolor. O painel aglomerado da mistura de cedro e pinus (T3, CP) exposto ao fungo de podridão parda Gloeophyllum trabeum apresentou o maior teor de lignina insolúvel que foi de $61,17 \%$, em consonância com a maior perda de massa que foi de 47,88\%. Resultados semelhantes ocorreram no trabalho de Costa (2009), estudando a biodeterioração da madeira de marupá e andiroba. $\mathrm{O}$ fungo de podridão parda levou a um aumento progressivo da lignina, evidenciado pelo aumento na intensidade relativa das bandas de lignina e a correspondente diminuição na intensidade das bandas de carboidratos.

Cerne, Lavras, v. 18, n. 1, p. 17-26, jan./mar. 2012
Tabela 5 - Valores dos teores de lignina solúvel e insolúvel da madeira de Cedro australiano e dos painéis puros ou em misturas com a madeira de pinus e eucalipto.

Table 5 - Values of soluble and insoluble lignin contents for solid Australian cedar wood, unblended panels and panels blended with pine and eucalyptus wood.

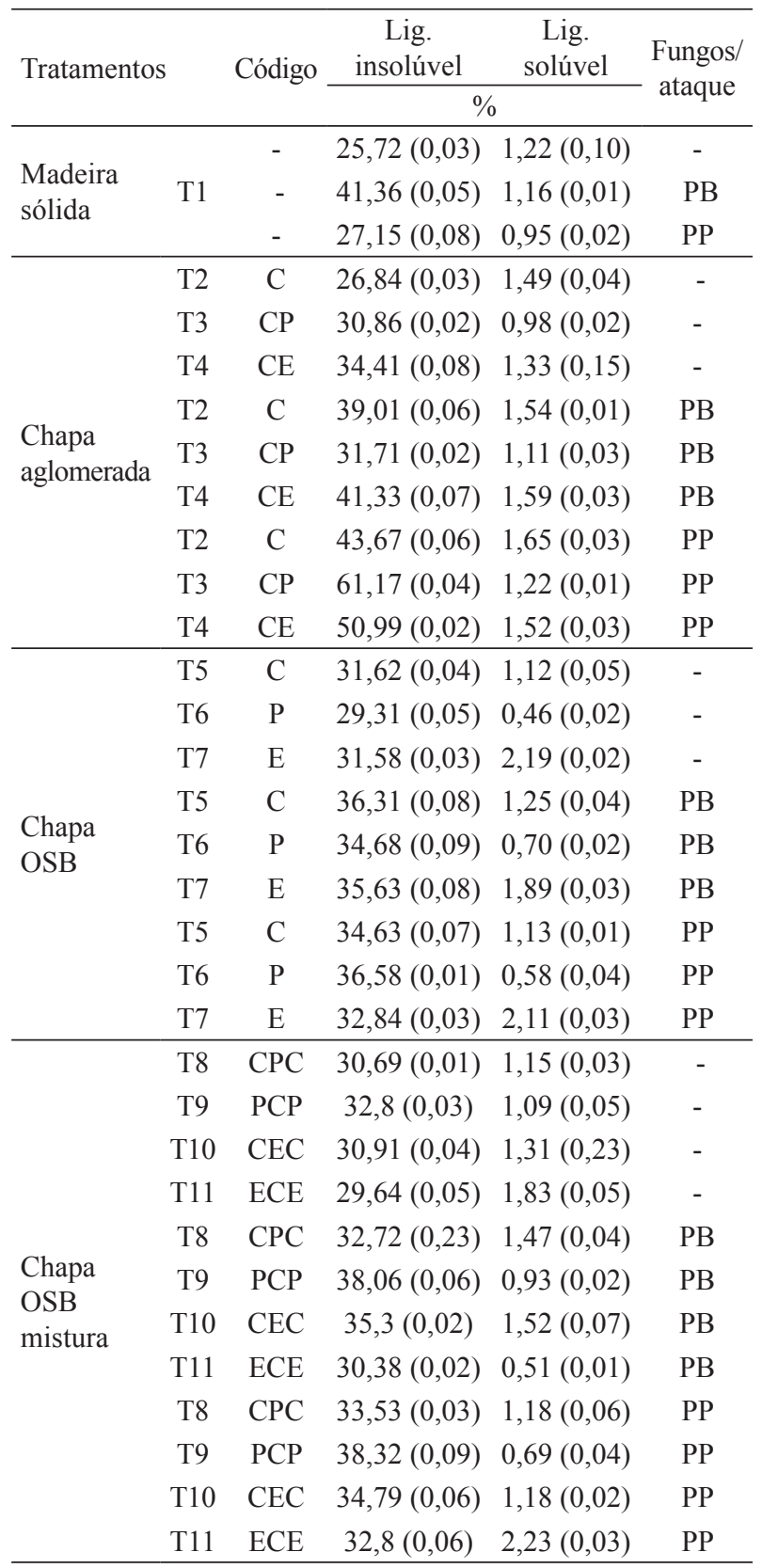

$\mathrm{PB}=$ Prodridão branca (Trametes versicolor); $\mathrm{PP}=$ Podridão parda (Gloeophyllum trabeum)

Dentro dos parênteses se encontram os desvios-padrão. 
Com relação aos painéis OSB, o teor de lignina insolúvel variou de $30 \%$ a $38 \%$. O painel OSB com sobreposição de camadas de pinus e cedro (T9, PCP) apresentou o maior teor de lignina insolúvel, dentre todos os tratamentos de painéis OSB confeccionados, que foi de $38,32 \%$ sendo corroborado pela maior perda de massa de $10,04 \%$, quando exposto ao fungo de podridão parda Gloeophyllum trabeum.

Com relação aos teores de lignina solúvel, os valores variaram de $0,46 \%$ a $2,23 \%$, sendo que os maiores teores de lignina solúvel não parecem correlacionar-se com os maiores teores de perda de massa das amostras atacadas.

\section{CONCLUSÕES}

Mediante os resultados obtidos pode-se concluir que:

- a espécie Cedro australiano apresenta vasos com porosidade em anéis semi-porosos; pontuações intervasculares alternas; parênquima axial paratraqueal escasso; parênquima marginal terminal; fibras libriformes com pontuações muito pequenas;

- as características anatômicas do Cedro australiano podem favorecer a biodeterioração por fungos da madeira e dos painéis reconstituídos;

- a madeira de cedro australiano foi classificada como moderadamente resistente;

- os painéis OSB foram classificados como resistentes e moderadamente resistentes para podridão branca, enquanto que, para a podridão parda todos foram altamente resistentes;

- os painéis aglomerados foram classificados como moderadamente resistentes, quanto à podridão branca. Enquanto que para a podridão parda, os tratamentos com cedro e cedro com eucalipto foram classificados como resistentes, e o tratamento com cedro e pinus foi classificado como não resistente;

- a variação total de coloração tanto para a madeira maciça como para os painéis aglomerados e OSB, após $\mathrm{o}$ ataque dos fungos, é mais pronunciada para o fungo de podridão parda (Gloeophyllum trabeum);

- o padrão de variação da coloração tem influência direta da perda de massa da madeira ou do painel;

- os teores de lignina insolúvel foram crescentes à medida que ocorreu a perda de massa provocada pelo ataque dos fungos, tanto para a madeira de cedro australiano como para os painéis;
- não foi observada relação entre a perda de massa, provocada pelo ataque dos fungos, com os teores de lignina solúvel.

\section{REFERÊNCIAS}

AMERICAN SOCIETY FOR TESTING AND MATERIALS.

D-2017: standard method for accelerated laboratory test of natural decay resistance for woods. Philadelphia, 2005. 5 p. (Annual Book of ASTM Standards, 410).

CARNEIRO, J. S.; EMMERT, L.; STERNADT, G. H.; MENDES, J. C.; ALMEIDA, G. F. Decay susceptibility of Amazon wood species from Brazil against white rot and brown rot decay fungi. Holzforshung, Stockholm, v. 63, n. 1, p. 767-772, Jan. 2009.

CORADIN, V. T. R.; CAMARGO, J. A. A. A estrutura anatômica da madeira e princípios para sua identificação. Brasília: LPF, 2002. 28 p.(Série técnica, 15).

CORADIN, V. T. R.; MARQUES, M. H. B.; CAMARGO, J. A. A.; MUNIZ, G. B. Chave de identificação das principais madeiras da floresta nacional do Tapajós. Brasília: LPF, 1991. 51 p. (Série técnica, 14).

COSTA, E. W. B. da. Natural decay resistance of wood. In: INTERNATIONAL CONGRESS OF PLANT PATHOLOGY, 2., 1975, New York. Proceedings... New York: SpringerVerlag, 2009. p. 203.

DIROL, D.; DEGLISE, X. Durabilité des bois et problèmes associés. Paris: Hermés Science, 2001. 415 p.

EATON, R. A.; HALE, M. D. C. Wood: decay pests and protection. Cambridge: Chapman and Hall, 1993. 556 p.

INTERNATIONAL ASSOCIATION OF WOOD ANATOMY. List of microscopic features hardwood identification. IAWA Bulletin, Leiden, v. 10, n. 3, p. 220-359, 1989.

KARTAL, S. N.; GREEN, F. Decay and termiteresistance médium density fiberboard (MDF) made from different wood species. International Biodeterioration e Biodegradation, Birmingham, v. 51, n. 3, p. 29-35, 2003.

LEPAGE, E. S. Manual de preservação de madeiras. São Paulo: IPT, 1986. v. 1, 342 p.

Cerne, Lavras, v. 18, n. 1, p. 17-26, jan./mar. 2012 
MANGLIAVORI, A.; MINETTI, M.; MOSCOVICH, F.; CRECHI, E. Dasometria en plantaciones comerciales de toona (Toona ciliate var. australis) em la Província de Salta. In: JORNADAS TÉCNICAS FORESTALES Y AMBIENTALES, 10., 2003, Eldorado. Anais...

Eldorado: Facultad de Ciências Forestales, 2003. CDROM.

NATIONAL RENEWABLE ENERGY LABORATORY. Chemical analysis and testing task: laboratory analytical procedure. Golden, 1996. 7 p.
OLIVEIRA, J. T. S.; SOUZA, L. C. de; DELLA LUCIA, R. M.; SOUZA JÚNIOR, W. P. de. Influência dos extrativos na resistência ao apodrecimento de seis espécies de madeira.

Revista Árvore, Viçosa, v. 29, n. 5, p. 819-826, set./out. 2005.

RICHTER, H. G.; BURGER, L. M. Anatomia da madeira. 2. ed. Curitiba: UFPR, 1978. 78 p.

ZABEL, R. A.; MORRELL, J. J. Natural decay resistance. In: Wood microbiology: decay and its prevention. San

Diego: Academic, 1992. p. 399-411.

Cerne, Lavras, v. 18, n. 1, p. 17-26, jan./mar. 2012 